\title{
Spinal Tuberculosis
}

\author{
Şafak EKINCi', Gülbanu HORZUM EKINCi² \\ ${ }^{1}$ Clinic of Orthopedics and Traumatology, Ağrı Military Hospital, Ağrı, Turkey \\ ${ }^{2}$ Clinic of Chest Diseases, Süreyyapaşa Chest Diseases and Chest Surgery Training and Research Hospital, Istanbul, Turkey
}

\section{Dear Editor,}

We read the article titled "Spinal Tuberculosis" in the last issue of your journal with great interest (1). As stated in the conclusion of the article, we would like to add some points regarding the importance of early diagnosis and treatment of spinal tuberculosis.

The skeletal area in which tuberculosis mostly occurs, leading to the most serious clinical result, is the spinal region (2-4). Because the progression of the disease is slow, some difficulties are encountered in its early diagnosis and treatment. Anti-inflammatory therapies that are administered until the establishment of an accurate diagnosis and the use of a corset do not stop the progression of the disease, and they even cause further treatment protocols to be more comprehensive $(5,6)$.

In Turkey, where tuberculosis is frequently observed, effective treatments have been being implemented for cases with spinal involvement in neurosurgery and orthopedics clinics for many years.

In the first case presented in the article, it was reported that the patient had back pain for 5 years, and after she presented to the clinic of internal diseases, treatment was initiated following the diagnosis of a lesion in the vertebrae; subsequently, she developed paraplegia within one month. Accordingly, it was concluded that the disease with slow progression was in the group of Type 2-3, according to the spinal tuberculosis classification of Gülhane Military Medical Academy (4), which was also referred to in the article, while transferring to the clinic of infectious diseases. In the cited article, it was clearly stated that surgical procedure must be applied for patients at advanced stage, who developed the formation of abscess (Type 1b).

In the second case, although the pathological examination of the patient revealed granulomatous lesion, she was administered a therapy that she could not remember, and she was operated because neurological deficit was observed after a year had passed.

Oguz et al. (4) reported that healing occurred without any neurological deficit in all 76 patients with spinal tuberculosis, five of whom were medically treated, between 1989 and 2002. In conclusion, we believe that for both the cases that were presented in the article, if the departments of neurosurgery and orthopedics had been consulted before the observation of neurological deficit findings, earlier healing without any complication would have been possible by administering tuberculosis treatment following surgery and using short-term and lighter treatment protocols without any requirement for long-term and difficult physiotherapy practices.

Considering that patients with complaints of back pain constitute the group of patients that often visit the outpatient clinics of physical treatment, neurosurgery, and orthopedics, it is obvious that the article will create an awareness regarding vertebral tuberculosis among physicians who examine this patient group. Therefore, we thank our honorable colleagues for preparing this article and for emphasizing on the importance of early diagnosis and treatment of spinal tuberculosis, and we extend our best compliments. 
Peer-review: Externally peer-reviewed.

Author Contributions: Concept - Ş.E.; Design - Ş.E.; Supervision - G.H.E.; Resource - G.H.E.; Materials - Ş.E.; Data Collection and/or Processing - G.H.E.; Analysis and/or Interpretation - Ş.E.; Literature Review - G.H.E.; Writer - Ş.E.; Critical Review - G.H.E.

Conflict of Interest: No conflict of interest was declared by the authors.

Financial Disclosure: The authors declared that this study has received no financial support.

\section{References}

1. Sirzai H, Dogu B, Demir S, Yılmaz FK, Kuran B. Spinal Tüberküloz. Turk J Phys Med Rehab 2015; 60:261-6. [CrossRef]
2. Boachi-Adjei O, Squillante RG. Tuberculosis of the spine. Orthop Clin North Am 1996;27:95-103.

3. Rezai AR, Lee M, Cooper PR, Errico TJ, Koslow M. Modern management of spinal tuberculosis. Neurosurgery 1995;36:87-97. [CrossRef]

4. Oguz E, Sehirlioglu A, Altinmakas M, Ozturk C, Komurcu M, Solakoglu $C$, et al. A new classification and guide for surgical treatment of spinal tuberculossis. Int Orthop 2008;32:127-33. [CrossRef]

5. Mehta JS, Bhojraj SY. Tuberculosis of thoracic spine. A classification based on the selection of surgical strategies. J Bone Joint Surg $\mathrm{Br}$ 2001;83:859-63. [CrossRef]

6. Moon MS, Moon YW, Moon JL, Kim SS, Sun DH. Conservative treatment of tuberculosis of the lumbar and lumbosacral spine. Clin Orthop 2002;398:40-9. [CrossRef] 